\title{
The impact of early neuraminidase inhibitor therapy on clinical outcomes in patients hospitalised with influenza A-related pneumonia: a multicenter, retrospective study
}

Liang Chen ${ }^{1 *}$, Xiudi Han², Yan Li Li ${ }^{3}$, Chunxiao Zhang ${ }^{4}$ and Xiqian Xing ${ }^{5}$

\begin{abstract}
Background: Guidelines emphasize prompt antiviral treatment in severe influenza patients. Although nearly a 50\% of severe influenza present with pneumonia, the effect of early ( $\leq 2$ days after illness onset) neuraminidase inhibitor (NAI) use on the clinical outcomes of influenza A-related pneumonia (FluA-p) has rarely been assessed. Furthermore, data about the administration of NAls in the real-world management of Flu-p in China are limited.

Methods: Data of patients hospitalised with FluA-p from five teaching hospitals in China from 1 January 2013 to 31 December 2018 were reviewed retrospectively. The impact of early NAI therapy on the outcomes in FluA-p patients, and the indications of early NAI administration by clinicians were evaluated by logistic regression analysis.

Results: In total, 693 FluA-p patients were included. Of these patients, 33.5\% (232/693) were treated early. After adjusting for weighted propensity scores for treatment, systemic corticosteroid and antibiotic use, a multivariate logistic regression model showed that early NAI therapy was associated with decreased risk for invasive ventilation [odds ratio $(O R) 0.511,95 \%$ confidence interval $(C I) 0.312-0.835, p=0.007)$ and 30-day mortality $(O R=0.533,95 \% \mathrm{Cl}$ $0.210-0.807, p<0.001)$ in FluA-p patients. A multivariate logistic regression model confirmed early NAl use (OR $0.415,95 \%$ Cl $0.195-0.858, p=0.001$ ) was a predictor for 30-day mortality in FluA-p patients and a positive rapid influenza diagnostic test was the only indication (OR 3.586, 95\% Cl 1.259-10.219, $p<0.001)$ related to the prescription of early NAI by clinicians.
\end{abstract}

Conclusions: Early NAI therapy is associated with better outcomes in FluA-p patients. Improved education and training of clinicians on the guidelines of influenza are needed.

Keywords: Neuraminidase inhibitor, Influenza a, Community-acquired pneumonia, Clinical outcome

\footnotetext{
* Correspondence: chenliang1995@sina.com

'Department of Infectious Disease, Beijing Jishuitan Hospital, 4th Medical College of Peking University, Beijing, China

Full list of author information is available at the end of the article
}

C C The Author(s). 2020 Open Access This article is licensed under a Creative Commons Attribution 4.0 International License, which permits use, sharing, adaptation, distribution and reproduction in any medium or format, as long as you give appropriate credit to the original author(s) and the source, provide a link to the Creative Commons licence, and indicate if changes were made. The images or other third party material in this article are included in the article's Creative Commons licence, unless indicated otherwise in a credit line to the material. If material is not included in the article's Creative Commons licence and your intended use is not permitted by statutory regulation or exceeds the permitted use, you will need to obtain permission directly from the copyright holder. To view a copy of this licence, visit http://creativecommons.org/licenses/by/4.0/ The Creative Commons Public Domain Dedication waiver (http://creativecommons.org/publicdomain/zero/1.0/) applies to the data made available in this article, unless otherwise stated in a credit line to the data. 


\section{Background}

Influenza is a highly contagious viral respiratory disease with global prevalence [1-4]. It is estimated that between 5 and $10 \%$ of the global population experience symptomatic influenza during an annual seasonal epidemic, including 3-5 million cases of severe illness and 290-650 thousand deaths from influenza-related respiratory illness $[5,6]$.

The neuraminidase inhibitors (NAIs), represented by oseltamivir, became the first anti-flu medication approved by the United Food and Drug Administration at the end of last century [7]. A randomized controlled trial (RCT) on uncomplicated outpatients within $48 \mathrm{~h}$ of symptom onset showed oseltamivir treatment decreased the duration of influenza by a median of $70 \mathrm{~h}$ and decreased patient-perceived severity of illness [8]. Subsequent observational studies suggested that severe influenza patients could also benefit from early ( $\leq 2$ days after illness onset) NAI administration [9-11]. Therefore, the American and Chinese guidelines recommended early initiation of NAI therapy in the patients at high-risk of severe influenza $[12,13]$.

Influenza-related pneumonia (Flu-p), including primary viral and secondary bacterial pneumonia, which is mostly caused by influenza A, is the major cause of hospitalizations and deaths due to influenza [14-16]. Previous studies on NAIs and severe influenza have rarely targeted Flu-p, especially in the Chinese population. Furthermore, although the Chinese guidelines emphasize prompt antiviral treatment in severe influenza patients after the 2009 influenza pandemic, there is limited data about the administration of NAIs in the real-world management of Flu-p in China.

We carried out a multicenter, retrospective study with two aims: 1) to evaluate the impact of early NAI therapy on the clinical outcomes in adolescent and adult patients hospitalised with FluA-p; and 2) to investigate the indications of early NAI administration by Chinese clinicians.

\section{Methods}

\section{Study design and population}

We conducted a retrospective review of the data of all hospitalised patients who tested positive for influenza A virus RNA detected in respiratory specimens at five teaching hospitals in Beijing, Shandong and Yunnan Provinces during the period from 1 January 2013 to 31 December 2018 (details of the five centers are shown in Additional file 1: Appendix 1). From these cases, we retrieved the data of patients with laboratory-confirmed influenza A-related pneumonia (FluA-p) onset in the community.

The following exclusion criteria were applied: (1) age < 14 years; (2) pneumonia onset $\geq 48 \mathrm{~h}$ after admission and hospitalised within the last 28 days [17]; and (3) immunocompromized status [17].

\section{Data collection}

The following data were retrospectively collected: demographic information, underlying disease (Additional file 1: Appendix 2), clinical manifestations, laboratory and radiological findings on admission, microbiological information, treatment (use of antiviral agents, antibiotics, corticosteroids and mechanical ventilation), clinical outcomes (admittance to the intensive care unit (ICU), 14day and 30-day mortality).

\section{Study definitions}

Patients with FluA-p were defined as patients with respiratory symptoms and a new pulmonary infiltrate on chest radiographs, combined with positive influenza virus A reverse transcription polymerase chain reaction (RT-PCR) tests during the influenza season in China. Early NAI use was defined as any NAI administered within 2 days after illness onset. Community-acquired respiratory co-infections resulting from coinfecting pathogens were identified using standard microbiologic procedures within the first $48 \mathrm{~h}$ after admission. The criteria for the definition of a community-acquired respiratory pathogen as the causative coinfecting etiology are shown in Additional file 1: Appendix file 3.

\section{Propensity scores for treatment}

Propensity scores (Ps) for the likelihood of NAI treatment were calculated for each patient using a multivariate logistic regression model according to the report by Hirano and Imbens [18]. The following covariates were included in the study: age, sex, comorbidities (body mass index $(\mathrm{BMI}) \geq 30 \mathrm{~kg} / \mathrm{m}^{2}$, smoking, pregnancy, asthma, chronic obstructive pulmonary disease, cardiovascular disease, cerebrovascular disease, malignant solid tumor, chronic kidney disease and diabetes), and CURB-65 scores (confusion, urea, respiratory rate, blood pressure, age $\geq 65$ years) as a measure of severity [19].

Weighted Ps (WPs) were calculated according to the following formula: WPs $=$ Pt/Ps in patients with early NAI use, while WPs $=(1-\mathrm{Pt}) /(1-\mathrm{Ps})$ in the control patients, where Pt represents the proportion of patients with early NAI use in the total patients included in the study.

\section{Statistical analysis}

All data were analyzed with SPSS 22.0 and measurement data were tested for normal distribution using the Kolmogorov-Smirnov test. Measurement data with normal distribution were reported as the mean \pm standard deviation. Measurement data with non-normal distribution was reported as the median. The categorical variables were analyzed by the Chi-square test or Fisher's exact test, and continuous variables were analyzed by Student's $t$-test or the Mann-Whitney U-test. A $p$-value of $<0.05$ was considered to indicate statistical significance 
and all probabilities were two-tailed. After adjusting for WPs for treatment, systemic corticosteroids and antibiotic use, a multivariate logistic regression model was used to evaluate the impact of early NAI therapy on the outcomes (invasive ventilation, 14-day mortality and 30day mortality) in the FluA-p patients. Variables with a $p$ values of $<0.1$ on univariate analysis were subsequently entered into the backward stepwise logistic regression analysis to identify risk factors for the 30-day mortality or the administration of NAI by the clinicians in FluA-p patients. Missing data in the covariates were included as a separate dummy category to allow for comparisons across the crude and adjusted analyses.

\section{Results}

\section{Screening process}

We screened 2187 hospitalised patients who tested positive for influenza A RNA. Overall, 693 immunocompetent adults and adolescent patients hospitalised with FluA-p were included in the final analysis (Fig. 1). Among these patients, 38.1\% (264/693) were infected with $\mathrm{A}(\mathrm{H} 1 \mathrm{~N} 1) \mathrm{pdm} 09$ and $11.0 \%$ (76/693) were infected with $\mathrm{A}(\mathrm{H} 3 \mathrm{~N} 2)$, while $50.9 \%$ (353/693) of patients were infected with an unclassified subtype. All patients received NAIs during the course of the disease, and 33.5\% $(232 / 693)$ were early NAI users.

\section{Overview of patients with FluA-p}

Overall, the median age of the patients was 61.0 years and $65.1 \%(451 / 693)$ were males. Fifty-eight percent of patients $(402 / 693)$ had at least one underlying disease.
Only 4.6\% (32/693) of patients had a consciousness disorder on admission. Respiratory rates $\geq 30$ times $/ \mathrm{min}$ and hypotension were identified in $17.5 \%(121 / 693)$ and $1.2 \%(8 / 693)$ of patients, respectively and $26.9 \%$ (172/ 639) of patients had $\mathrm{pO}_{2} / \mathrm{FiO}_{2} \leq 250 \mathrm{mmHg}$. Multilobar infiltrate and pleural effusion in chest radiology was observed in $78.8 \%(546 / 693)$ and $16.6 \%(115 / 693)$ of patients, respectively (Table 1 ).

As shown in Additional file 1: Appendix file 4, 38.2\% (265/693) of FluA-p patients were coinfected with other community-acquired respiratory pathogens, with Streptococcus pneumoniae (33.2\%) as the most common etiology, followed by Klebsiella pneumoniae (30.6\%) and Staphylococcus aureus (20.4\%).

All patients were treated with antibiotics and 19\% of patients (132/693) received systemic corticosteroids during hospitalisation. The 30-day mortality was $19.6 \%$ (136/693) (Table 1).

\section{The risk factors for 30-day mortality in FluA-p patients} According to the survival status at 30 days after admission, the patients were divided into survival and deceased groups. The baseline characteristics of the patients in the survival and deceased groups are shown in the Table 1. There were no significant differences in terms of age and sex between the two groups. Cardiovascular disease, smoking history, confusion, leukocytes $>10 \times 10^{9} / \mathrm{L}$, lymphocytes $<0.8 \times 10^{9} / \mathrm{L}, \quad \mathrm{Hb}<100 \mathrm{~g} / \mathrm{L}$, BUN $>7 \mathrm{mmol} / \mathrm{L}$, arterial $\mathrm{pH}<7.35$ on admission, early use of NAIs and systemic corticosteroids during hospitalization were more common in the deceased

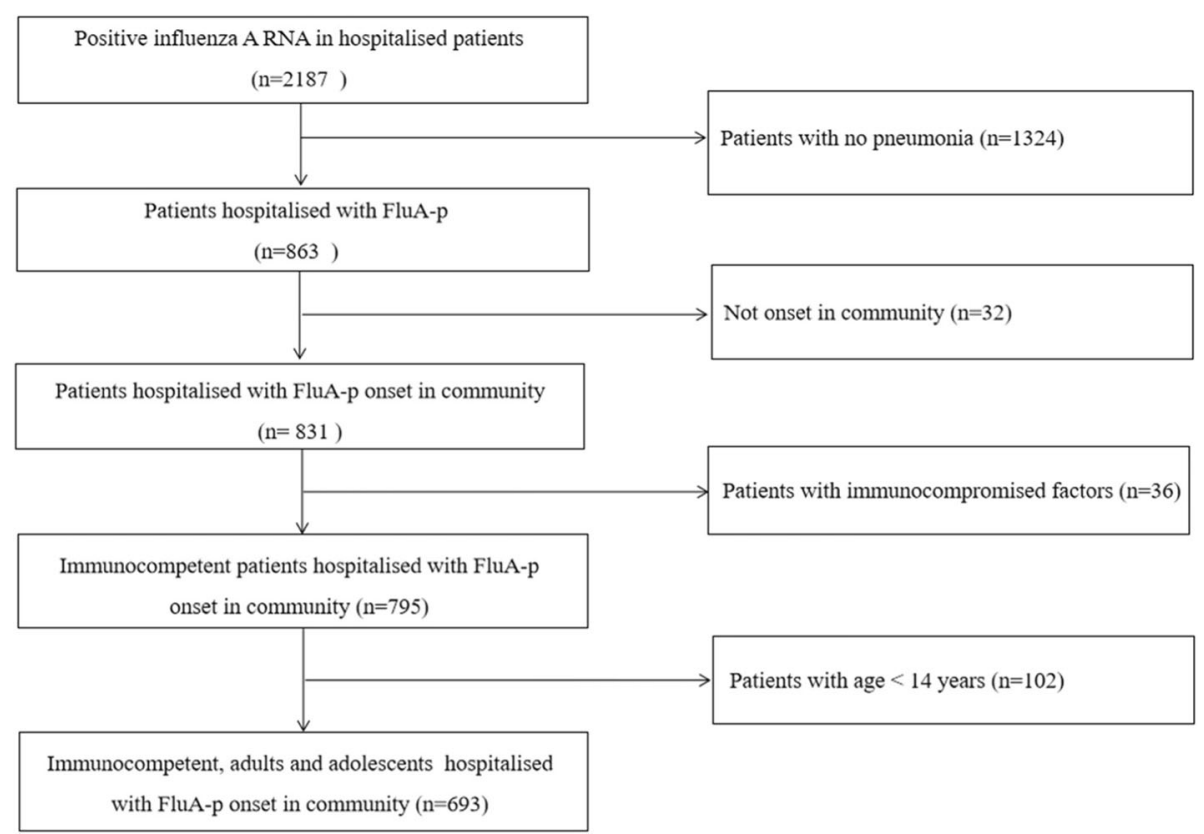

Fig. 1 Patient screening algorithm for FluA-p 
Table 1 The baseline characteristics of patients in the deceased and survival groups

\begin{tabular}{|c|c|c|c|c|}
\hline Variables & Total $(n=693)$ & Deceased group $(n=136)$ & Survival group $(n=557)$ & $p$-value \\
\hline Male $\left(n_{1}\right)$ & $461(66.5)$ & $92(67.6)$ & $369(66.2)$ & 0.757 \\
\hline Age (median, IQR, years) & $61.0(36.0-73.0)$ & $61.5(28.0-76.0)$ & $59.0(36.0-72.0)$ & 0.963 \\
\hline $\mathrm{BMI} \geq 30 \mathrm{~kg} / \mathrm{m}^{2}(n, \%)^{\mathrm{a}}$ & $48(6.9)$ & $0(0.0)$ & $48(8.6)$ & $<0.001$ \\
\hline \multicolumn{5}{|l|}{ Comorbidities ( $n, \%)$} \\
\hline Hypertension & $252(36.4)$ & $48(35.3)$ & $204(36.6)$ & 0.772 \\
\hline Cardiovascular disease ${ }^{a}$ & $136(19.6)$ & $48(35.3)$ & $88(15.8)$ & $<0.001$ \\
\hline Diabetes mellitus & $92(13.3)$ & $14(10.3)$ & $78(14.0)$ & 0.253 \\
\hline Cerebrovascular disease & $72(10.4)$ & $10(7.4)$ & $62(11.1)$ & 0.195 \\
\hline $\mathrm{COPD}^{\mathrm{a}}$ & $40(5.8)$ & $3(2.2)$ & $37(6.6)$ & 0.047 \\
\hline Asthma & $19(2.7)$ & $2(1.5)$ & $17(3.1)$ & 0.222 \\
\hline Chronic kidney disease & $16(2.3)$ & $6(4.4)$ & $10(1.8)$ & 0.133 \\
\hline Malignant solid tumor & $16(2.3)$ & $0(0.0)$ & $16(2.9)$ & 0.193 \\
\hline Smoking history ${ }^{a}$ & $243(35.1)$ & $68(50.0)$ & $175(31.4)$ & $<0.001$ \\
\hline \multicolumn{5}{|l|}{ Clinical and radiologic characteristics $(n, \%)$} \\
\hline Respiratory rates $\geq 30$ times/min & $121(17.5)$ & $25(18.4)$ & $96(17.2)$ & 0.752 \\
\hline Confusion $^{\mathrm{a}}$ & $32(4.6)$ & $32(23.5)$ & $0(0.0)$ & $<0.001$ \\
\hline $\mathrm{SBP}<90 \mathrm{mmHg}$ & $8(1.2)$ & $0(0.0)$ & $8(1.4)$ & 0.338 \\
\hline Leukocytes $>10 \times 10^{9} / \mathrm{L}^{\mathrm{a}}$ & $118(17.0)$ & $42(30.9)$ & $76(13.6)$ & $<0.001$ \\
\hline Lymphocytes $<0.8 \times 10^{9} / \mathrm{L}^{\mathrm{a}}$ & 299/677 (44.2) & $120(88.2)$ & 179/541 (33.1) & $<0.001$ \\
\hline $\mathrm{Hb}<100 \mathrm{~g} / \mathrm{L}^{\mathrm{a}}$ & $69(10.0)$ & $34(25.0)$ & $35(6.3)$ & $<0.001$ \\
\hline $\mathrm{ALB}<35 \mathrm{~g} / \mathrm{L}$ & $58 / 639(9.1)$ & $12 / 131(9.2)$ & $46 / 508(9.1)$ & 0.970 \\
\hline $\mathrm{BUN}>7 \mathrm{mmol} / \mathrm{L}^{\mathrm{a}}$ & $183 / 685(26.7)$ & $97(71.3)$ & $86 / 549(15.7)$ & $<0.001$ \\
\hline $\mathrm{BG}>11 \mathrm{mmol} / \mathrm{L}$ & $48(6.9)$ & $8(5.9)$ & $40(7.2)$ & 0.397 \\
\hline Arterial $\mathrm{pH}<7.35^{\mathrm{a}}$ & 120/639 (18.8) & $60 / 136(44.1)$ & 60/503 (11.9) & $<0.001$ \\
\hline $\mathrm{pO}_{2} / \mathrm{F}_{\mathrm{i}} \mathrm{O}_{2} \leq 250 \mathrm{mmHg}{ }^{\mathrm{a}}$ & $172 / 639(26.9)$ & 28/136 (20.6) & 144/503 (28.6) & 0.061 \\
\hline Pleural effusion ${ }^{a}$ & $120(17.3)$ & $36(26.5)$ & $84(15.1)$ & $<0.001$ \\
\hline Early NAI use ${ }^{a}(n, \%)^{a}$ & $232(33.5)$ & $60(43.4)$ & $172(30.9)$ & 0.003 \\
\hline Duration from illness onset to NAI use (days, median, IQR) ${ }^{a}$ & $3.0(1.0-4.0)$ & $2.5(1.0-3.0)$ & $3.0(1.0-4.0)$ & 0.004 \\
\hline Systemic corticosteroid use $(n, \%)^{a}$ & $132(19.0)$ & $60(44.1)$ & $72(12.9)$ & $<0.001$ \\
\hline Coinfection with other pathogens $(n, \%)^{a}$ & $265(38.2)$ & $84(61.8)$ & $181(32.5)$ & $<0.001$ \\
\hline
\end{tabular}

${ }^{a}$ Variables cited in the table above were the candidates which were entered into the multivariate logistic regression model. The bolded values are $p$-values $<0.05$, which represent significant differences between survival group and deceased group. IQR Interquartile range, $B M I$ Body mass index, COPD Chronic obstructive pulmonary disease, SBP Systolic blood pressure, $\mathrm{Hb}$ Hemoglobin, BG Blood glucose, $A L B$ Albumin, BUN Blood urea nitrogen, $\mathrm{pO}_{2} / \mathrm{FiO}_{2}$ Arterial pressure of oxygen/ fraction of inspiration oxygen, NAls Neuraminidase inhibitors; a: Neuraminidase inhibitor refers to any dose of oseltamivir, zanamivir or peramivir

group compared with the survival group, while $\mathrm{BMI} \geq 30$ $\mathrm{kg} / \mathrm{m}^{2}$ and COPD were less common. Although more patients in the deceased group were coinfected with other pathogens, there was no significant differences in the spectrum of etiologies (Additional file 1: Appendix file 4).

The multivariate logistic regression model confirmed early NAI therapy [odds ratio $(O R)$ 0.415, 95\% confidence interval (CI) $0.195-0.858, p=0.001]$, cardiovascular disease (OR 3.189, 95\% CI 1.300-7.892, $p<0.001)$, smoking history (OR 3.294, 95\% CI 1.151-9.429, $p<0.001)$, lymphocytes $<0.8 \times 10^{9} / \mathrm{L}(O R \quad 4.080,95 \%$ CI 1.321-12.596, $p<0.001), \mathrm{BUN}>7 \mathrm{mmol} / \mathrm{L}(O R 2.158,95 \%$ CI 1.0844.690, $p<0.001)$ and $\mathrm{pO}_{2} / \mathrm{FiO}_{2} \leq 250 \mathrm{mmHg}(\mathrm{OR}$ 4.344,
Table 2 The risk factors for the 30-day mortality in FluA-CAP patients

\begin{tabular}{lll}
\hline Variable & OR $(95 \% \mathrm{Cl})$ & $p$-value \\
\hline Cardiovascular disease & $3.189(1.300-7.892)$ & $<0.001$ \\
Smoking history & $3.294(1.151-9.429)$ & $<0.001$ \\
Lymphocytes $<0.8 \times 10^{9} / \mathrm{L}$ & $4.080(1.321-12.596)$ & $<0.001$ \\
$\mathrm{BUN}>7 \mathrm{mmol} / \mathrm{L}$ & $2.158(1.084-4.690)$ & $<0.001$ \\
$\mathrm{PO}_{2} / \mathrm{F}_{\mathrm{i}} \mathrm{O}_{2} \leq 250 \mathrm{mmHg}$ & $4.344(2.050-9.203)$ & $<0.001$ \\
Early NAl therapy & $0.415(0.195-0.858)$ & 0.001 \\
\hline
\end{tabular}

OR Odd ratio, $\mathrm{Cl}$ Confidence interval 
95\% CI 2.050-9.203, $p<0.001)$ were independent risk factors for 30-day mortality in FluA-p patients (Table 2).

\section{The impact of early NAI use on the clinical outcomes of FluA-p patients}

In the univariate analysis, early NAI therapy was associated with increased risk for 30-day mortality, but not with invasive ventilation or 14-day mortality.

After adjusting for WPs for treatment, systemic corticosteroid and antibiotic use, a multivariate logistic regression model showed that early use of NAI was associated with decreased risk of invasive ventilation (OR 0.511, 95\% CI 0.312-0.835, $p=0.007$ ), 14-day mortality (OR 0.477, 95\% CI 0.124-0.744, $p<0.001)$ and 30day mortality (OR 0.533, 95\% CI 0.210-0.807, $p<0.001$ ) in FluA-p patients (Table 3).

Figure 2 shows association between early NAI therapy and the outcomes of FluA-p patients before and after adjusting for confounders.

\section{The risk factors for early NAI administration prescribed by clinicians}

Logistic regression analysis allowed us to further explore the factors predictive of NAI use in FluA-p patients. All the potential factors screened in the univariate analysis with $p<$ 0.1 variables were included in the regression model: male, age $\geq 65$ years old, cardiovascular disease, diabetes mellitus, cerebrovascular disease, COPD, asthma, chronic kidney disease, malignant solid tumor, axillary temperature $\geq 38^{\circ} \mathrm{C}$, cough, chest pain, confusion, $\mathrm{SBP}<90 \mathrm{mmHg}$, leukocytes $>$ $10 \times 10^{9} / \mathrm{L}$, leukocytes $<4.0 \times 10^{9} / \mathrm{L}$, lymphocytes $<0.8 \times$ $10^{9} / \mathrm{L}, \mathrm{PO}_{2} / \mathrm{FiO}_{2} \leq 250 \mathrm{mmHg}$, pleural effusion and positive for RIDTs (Additional file 1: Appendix file 5).

A multivariate logistic regression model suggested that positive RIDTs (OR 6.504, 95\% CI 1.671-25.323, $p=$ 0.007 ) was the only predictor for early NAI administration by clinicians in the FluA-p patients (Table 4).

Figure 3 shows similar proportions of early NAI administration and positive RIDT in FluA-p patients treated during the study period, both of which fluctuated up and down by $30 \%$.

\section{Discussion}

Our study had two important findings. First, compared with late use of NAI, early initiation of NAI therapy was associated with better outcomes in FluA-p patients and second, in real-world management of FluA-p patients, positive RIDT was the only indication for early NAI administration by the Chinese clinicians.

Previous studies have shown that the mortality due to influenza-related pneumonia ranged from 5 to $50 \%$ [20, 21 ]. In our study, the 30-day mortality rate was $19.6 \%$, which was in accordance with these previous reports. A RCT is considered to be the most effective approach to the evaluation of the effect of a medication [22]. The World Health Organization have formally endorsed the use of NAIs in high-risk or severely ill patients with influenza; therefore, RCTs in populations such as patients with influenza-related pneumonia are unlikely due to ethical concerns. Unlike RCTs, observational studies are subject to selective bias, and a large number of confounders may have a significant impact on the outcomes $[23,24]$. Patients with more severe disease may tend to receive treatment earlier (or later), so the therapeutic effect will be exaggerated (or attenuated). For example, in our study, more deceased patients received early NAI treatment, and the period from disease onset to the initiation of NAI treatment was slightly shorter. After control for other confounders (e.g., obesity, cardiovascular disease, illness severity at admission and systemic corticosteroid use), the direction of the association between early use of NAI and mortality changed. To minimize the selective bias, we used two methodologies to control for the potential confounders. Both sets of results confirmed the association of early NAI therapy with better outcomes, with very similar $O R$ values for mortality. Muthuri [25] conducted a meta-analysis of 20,634 severely ill patients with (H1N1) pdm09 infections from nine centers all over the world using individual data rather than group data for greater accuracy. This analysis revealed that early NAI therapy was associated with decreased risk of invasive ventilation [hazard ratio $(H R)$ 0.68, 95\% CI 0.54-0.85) and mortality (HR 0.70, 95\% CI $0.55-0.88)$ in influenza-related pneumonia compared with late NAI therapy. In fact, although few studies have focused on influenza-related pneumonia, most showed early NAI use improved the clinical outcomes in severe cases of influenza, including reducing the incidence of complications and decreasing the mortality rate [26-28]. A study suggested a potential benefit of NAI treatment

Table 3 The impact of early NAI therapy on the clinical outcomes of FluA-CAP patients

\begin{tabular}{|c|c|c|c|c|c|c|}
\hline \multirow[t]{2}{*}{ Variable } & \multicolumn{2}{|l|}{ Patients ( $n, \%)$} & \multicolumn{2}{|c|}{ Univariate logistic analysis } & \multicolumn{2}{|c|}{ Multivariate logistic analysis } \\
\hline & Early NAI use group $(n=232)$ & Control group $(n=461)$ & OR (95\% Cl) & $p$-value & $\mathrm{a}_{\mathrm{a} O R}(95 \% \mathrm{Cl})$ & $p$-value \\
\hline Invasive ventilation & $52(22.4)$ & $106(23.0)$ & $0.897(0.612-1.317)$ & 0.577 & $0.511(0.312-0.835)$ & 0.007 \\
\hline 14-day mortality & $32(13.8)$ & $48(10.4)$ & $1.377(0.853-2.221)$ & 0.190 & $0.477(0.124-0.744)$ & $<0.001$ \\
\hline 30-day mortality & $60(25.9)$ & $76(16.5)$ & $1.767(1.205-2.592)$ & 0.004 & $0.533(0.210-0.807)$ & $<0.001$ \\
\hline
\end{tabular}

${ }^{\mathrm{a}}$ Adjusted for weighted propensity scores for treatment, systemic corticosteroid and antibiotic use 


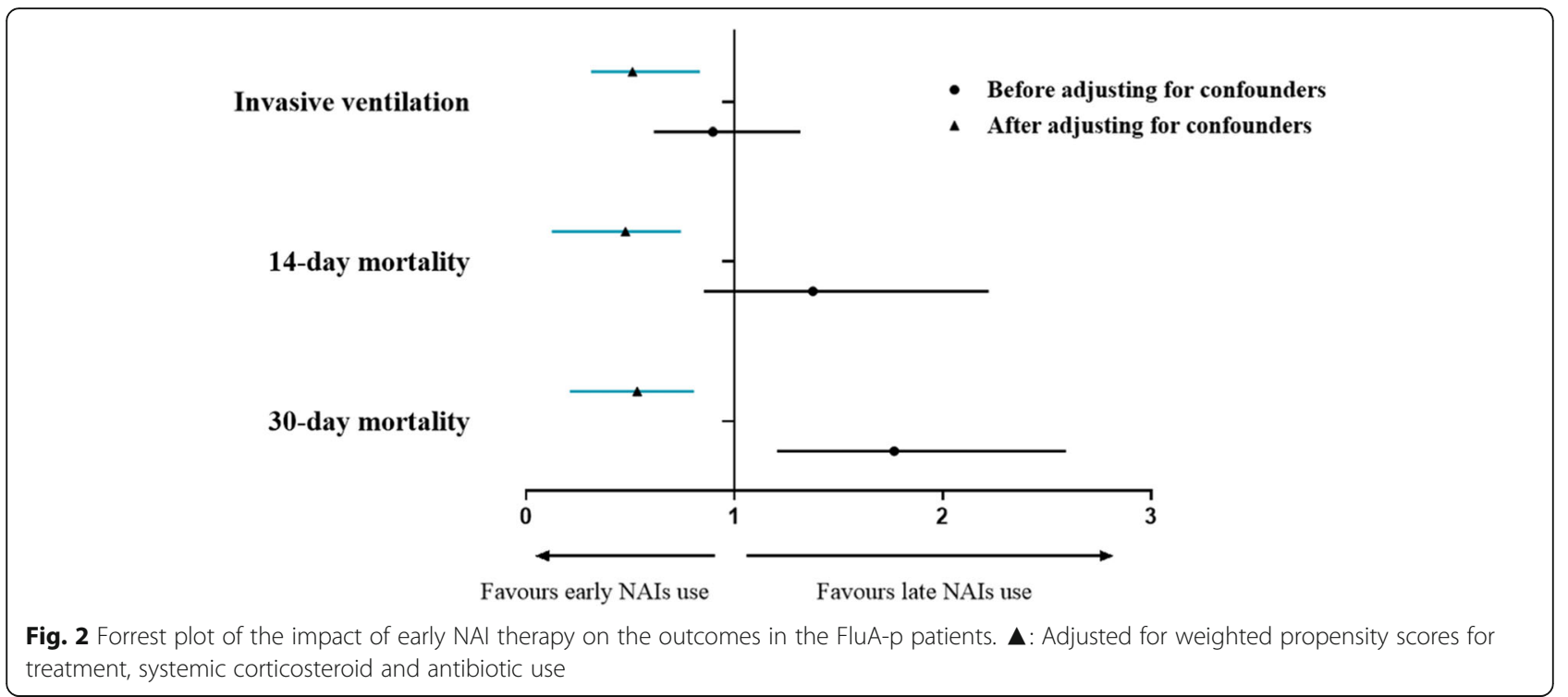

even $48 \mathrm{~h}$ after the onset of symptoms in the very sick patients [26].

Choi [29] conducted a retrospective study of 508 patients hospitalised with severe influenza during 2010 and 2011 , with $28.3 \%$ of the patients complicated by pneumonia. The results of this study showed that early NAI therapy was associated with decreased risk of ICU admission, but not with the in-hospital mortality; however, the timing of NAI use might be a risk factor for ICU admittance, an association that was not analyzed. In addition, $28.1 \%$ of patients in this study were infected with influenza $B$, and the authors speculated that the discrepancy with the results of others was due to the fact that NAIs are less effective against influenza B compared to influenza A. However, two other studies showed that patients with severe influenza $B$ also benefited from NAI therapy [10, 30].

Although RT-PCR detection of RNA has become the standard diagnostic test for influenza infection, its extensive use is limited by many factors, such as staff expertise, equipment maintenance, testing procedures and many other aspects of laboratory operations, in addition to the cost [31, 32]. Rapid influenza diagnostic tests (RIDTs) have three main advantages of low cost, technical simplicity and rapid results that can be obtained in 10 to $15 \mathrm{~min}$, which is significantly faster than the period of $1 \mathrm{~h}$ or more required for RT-PCR methods [33, 34]. However, RIDTs are less sensitive than RT-PCR and require $10^{4}$ to $10^{6}$ infectious influenza particles for a

Table 4 The risk factors for early NAI administration by the clinicians

\begin{tabular}{lcl}
\hline Variable & $p$-value & OR $(95 \%(l)$ \\
\hline Positive for RIDTs & $<0.001$ & $3.586(1.259-10.219)$ \\
\hline RIDTs Rapid influenza diagnostic tests &
\end{tabular}

positive result [35]. Previous reports showed more than $40 \%$ false-negative results obtained by RIDTs [36, 37]. During epidemics, the Chinese guidelines on influenza recommend that the primary diagnosis of influenza infection is dependent on influenza-like illness (ILI) and some studies have shown the accuracy of ILI is between 60 and $70 \%$ compared with RT-PCR methods in the diagnosis of influenza $[38,39]$. The guidelines also recommend early identification and antiviral treatment in patients at high-risk of severe influenza, according to host factors (e.g., age, comorbidities, and pregnancy) and clinical presentations (e.g., consciousness disorder, respiratory distress, hypotension, and hypoxemia).

In our study, the patients receiving early NAI therapy were younger, with a lower frequency of underlying disease, and the indexes of illness severity, such as shortness of breath, confusion and oxygenation status, were not worse than those of the control patients. A multivariate logistic regression analysis showed that a positive RIDT was the only indication of early NAI administration by the clinicians. The proportions of patients with a positive RIDT and receiving early NAI therapy were very similar, accounting for nearly one-third of the total patients each year. Previous reports revealed that between 10 and $60 \%$ of severe influenza patients received early NAI treatment [40-42]. Data for patients' delay in visiting the doctor and unavailability of medication, which could not be collected and evaluated in our retrospective study; however, our results indicated that over-reliance on the results of RIDTs in influenza diagnosis, and ignorance of the clinical characteristics and host factors that identify patients at high-risk of severe influenza contributed to two-thirds of influenza pneumonia patients missing the chance of receiving early NAI therapy. As all the participating centers were teaching hospitals, 


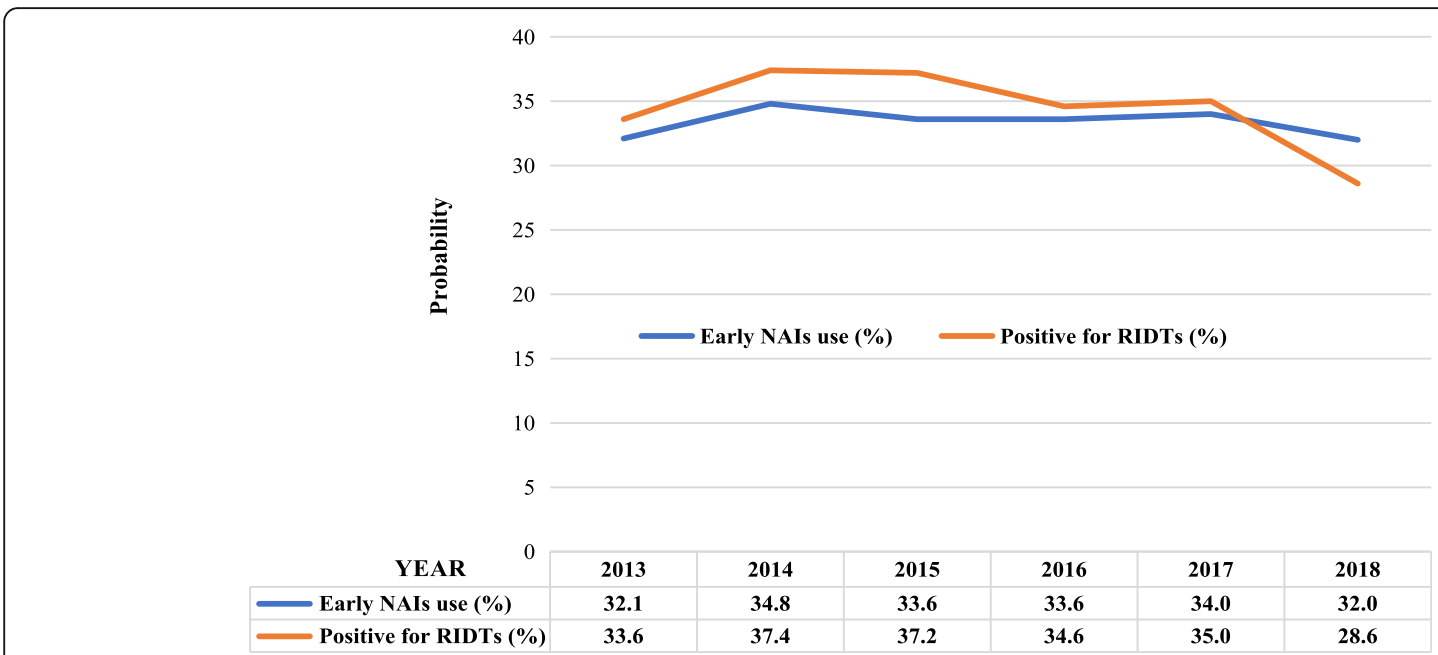

Fig. 3 The proportion of early NAI treatment and RIDT-positive FluA-p patients treated during 2013-2018 in China

we thought this phenomenon might be universal and representative.

There are some limitations specific to our study that should be mentioned. First, in addition to the retrospective nature of this study, some missing data might limit the accuracy of our results. Second, more than one-third of the patients had not undergone influenza subtype testing and other respiratory tract viruses were not routinely detected; thus, we could not exclude coinfection with other viruses. Third, a few studies indicated that the antiviral susceptibility profile of influenza A viruses in immunocompromized patients was not the same as that in immunocompetent hosts $[43,44]$. Therefore, the conclusions of our research should be assessed prudently before being applied in immunocompromized patients. Finally, due to the retrospective study design, vaccination data could not be retrieved to allow adjustment for this potential in the logistic regression analysis.

\section{Conclusions}

Our study confirmed that early initiation of NAI therapy is associated with better outcomes in FluA-p patients, which supported the recommendations for NAI use in the current guidelines. Our findings also suggest that better education and training of clinicians on current influenza guidelines in China are needed to improve the management of severe influenza.

\section{Supplementary information}

Supplementary information accompanies this paper at https://doi.org/10. 1186/s12879-020-05322-x.

Additional file 1 Appendix 1: Details of participating centers.

Appendix 2. Definition of underlying diseases. Appendix 3. Definition

of microbiological criteria of coinfected with other pathogens. Appendix
4. coinfection with other community-acquired pathogens. Appendix 5. The comparison of patients in the early NAls use group and the control group.

\section{Abbreviations}

Flu-p: Influenza-related pneumonia; NAl: Neuraminidase inhibitor RCT: Randomized controlled trial; OR: Odds ratio; HR: Hazard ratio; 95\% IC: 95\% Interval confidence; FluA-p: Influenza A-related pneumonia; RTPCR: Reverse transcription-polymerase chain reaction; IQR: Interquartile range BMI: Body mass index; COPD: Chronic obstructive pulmonary disease; SBP: Systolic blood pressure; Hb: Hemoglobin; BG: Blood glucose; ALB: Albumin; BUN: Blood urea nitrogen; $\mathrm{PH}$ : Hydrogen ion index; $\mathrm{pO}_{2} /$ $\mathrm{FiO}_{2}$ : Arterial pressure of oxygen/fraction of inspiration oxygen; ICU: Intensive care unit; RIDTs: Rapid influenza diagnostic tests; ILI: Influenza-like illness

\section{Acknowledgments}

The authors would like to express their gratitude to BMCSCI (http://www bmcscience.com/) for the expert linguistic services provided.

\section{Authors' contributions}

Study concept and design: LC, XdH. Acquisition of data: LC, XdH, YIL, CXZ, XqX. Statistical analysis of data: LC. Drafting of the manuscript: LC. Critical revision of the manuscript for important intellectual content: $\mathrm{XdH}, \mathrm{XqX}$. All authors agree with the article submission. All authors read and approved the final manuscript.

\section{Funding}

This study is founded by Beijing JST research (ZR-201921). The funder had no role in the design of the study and collection, analysis, and interpretation of data and in writing the manuscript.

\section{Availability of data and materials}

The datasets used and/or analyzed during the current study is available from the corresponding author on reasonable request.

Ethics approval and consent to participate

The study design was approved by the Ethics Committee of Beijing Jishuitan Hospital (No.201911-15). Given the retrospective nature of the study, the Ethics Committee determined that an informed consent was not necessary. This study used data collected from patient records while maintaining patient anonymity. No administrative permissions were required to access the raw data. 


\section{Competing interests}

The authors declare no competing interests.

\section{Author details}

'Department of Infectious Disease, Beijing Jishuitan Hospital, 4th Medical College of Peking University, Beijing, China. ${ }^{2}$ Department of Pulmonary and Critical Care Medicine, Qingdao Municipal Hospital, Qingdao City, Shandong Province, China. ${ }^{3}$ Department of Infectious Diseases and Clinical

Microbiology, Beijing Chao-Yang Hospital, Capital Medical University, Beijing, China. ${ }^{4}$ Department of Pulmonary and Critical Care Medicine, Beijing Huimin Hospital, Beijing, China. ${ }^{5}$ Department of Pulmonary and Critical Care Medicine, the 2nd People's Hospital of Yunnan Province, Kunming City, Yunnan Province, China.

\section{Received: 4 January 2020 Accepted: 3 August 2020}

Published online: 26 August 2020

\section{References}

1. Peteranderl C, Herold S, Schmoldt C. Human influenza virus infections. Semin Respir Crit Care Med. 2006;37(4):487-500.

2. Neuzil KM, Bresee JS, de la Hoz F, Johansen K, Karron RA, Krishnan A, et al. Data and product needs for influenza immunization programs in low- and middle-income countries: rationale and main conclusions of the WHO preferred product characteristics for next-generation influenza vaccines. Vaccine. 2017;35(43):5734-7.

3. Johnson NPAS, Mueller J. Updating the accounts: global mortality of the 1918-1920 "Spanish" influenza pandemic. Bull Hist Med. 2002;76(1):105-15.

4. Spreeuwenberg $P$, Kroneman M, Paget J. Reassessing the global mortality burden of the 1918 influenza pandemic. Am J Epidemiol. 2018;187(12): 2561-7.

5. Ly S, Arashiro T, leng V, Tsuyuoka R, Parry A, Horwood P, et al. Establishing seasonal and alert influenza thresholds in Cambodia using the WHO method: implications for effective utilization of influenza surveillance in the tropics and subtropics. Western Pac Surveill Response J. 2017;8(1):22-32.

6. Lozano R, Naghavi M, Foreman K, Lim S, Shibuya K, Aboyans V, et al. Global and regional mortality from 235 causes of death for 20 age groups in 1990 and 2010: a systematic analfor the global burden of disease study 2010. Lancet. 2012;380(9859):2095-128.

7. von Itzstein M, Wu WY, Kok GB, Pegg MS, Dyason JC, Jin B, et al. Rational design of potent sialidase-based inhibitors of influenza virus replication. Nature. 1993;363(6428):418-23.

8. Treanor JJ, Hayden FG, Vrooman PS, Barbarash R, Bettis R, Riff D, et al. Efficacy and safety of the oral neuraminidase inhibitor oseltamivir in treating acute influenza: a randomized controlled trial. US Oral Neuraminidase Study Group. JAMA. 2000;283(8):1016-24.

9. Hiba V, Chowers M, Levi-Vinograd I, Rubinovitch B, Leibovici L, Paul M. Benefit of early treatment with oseltamivir in hospitalised patients with documented 2009 influenza a (H1N1): retrospective cohort study. J Antimicrob Chemother. 2011;66(5):1150-5.

10. McGeer A, Green KA, Plevneshi A, Shigayeva A, Siddiqi N, Raboud J, et al. Antiviral therapy and outcomes of influenza requiring hospitalization in Ontario, Canada. Clin Infect Dis. 2007;45(12):1568-75.

11. Sugaya N, Shinjoh M, Mitamura K, Takahashi T. Very low pandemic influenza a (H1N1) 2009 mortality associated with early neuraminidase inhibitor treatment in Japan: analysis of 1000 hospitalised children. J Inf Secur. 2011 63(4):288-94.

12. Uyeki TM, Bernstein HH, Bradley JS, Englund JA, File TM, Fry AM, et al. Clinical practice guidelines by the Infectious Diseases Society of America: 2018 update on diagnosis, treatment, chemoprophylaxis, and institutional outbreak Management of Seasonal Influenza a. Clin Infect Dis. 2019;68(6): e1-e47.

13. National Health Commission of the People's Republic of China. Clinica guidance for patients with influenza infection. http://www.nhc.gov.cn/xxgk/ pages/viewdocumentjsp?\%20dispatchDate=\&staticUrl=\%2Fyzygj\%2Fpqt\%2 F201811\%2Fdd748b43df0640e0bf\%2033c526ca8c9ddfshtml\&wenhao=\%E5\% 9B\%BD\%E5\%8D\%AB\%E5\%8A\%9E\%20\%E58CBB\%E5\%87\%BD\%E380942018\% E380951020\%E58F\%B7\%20\&utitle=\%E5\%85B3\%E4\%BA\%8E\%E8\%BF\%9B\% E4\%B8\%80\%E6\%AD\%\%20A5E5\%8A\%A0\%E5\%BC\%BA\%E6\%B5\%81\%E8A1\% 8C\%E6\%80\%A7\%E6\%2084\%9F\%E586\%92\%E5\%8C\%BB\%E79697\%E5\%B7\% A5\%E4\%BD\%9C\%E7\%20\%9A\%84\%E9809A\%E79F\%A5\&topictype=\&topic= \&publishedOrg=\%E5\%\%208C\%BB\%E6\%94\%BF\%E5\%8C\%BB\%E7\%AE\%A1\%
E5\%B1\%80\&indexNum=\%20000013610\%2F2018-00308\&manuscriptld=dd74 8b43df0640e0bf33c526ca208c9ddf

14. Ishiguro T, Takayanagi N, Kanauchi T, Uozumi R, Kawate E, Takaku Y, et al. Clinical and radiographic comparison of influenza virus-associated pneumonia among three viral subtypes. Intern Med. 2016;55(7):731-7.

15. Li M, Bolker BM, Dushoff J, Ma J, Earn DJD. Patterns of seasonal and pandemic influenza-associated health care and mortality in Ontario, Canada. BMC Public Health. 2019;19(1):1237.

16. Jain S, Kamimoto L, Bramley AM, Schmitz AM, Benoit SR, Louie J, et al. Hospitalised patients with 2009 H1N1 influenza in the United States, AprilJune 2009. N Engl J Med. 2009;361(20):1935-44.

17. Chen L, Zhou F, Li H, Xing X, Han X, Wang Y, et al. Disease characteristics and management of hospitalised adolescents and adults with communityacquired pneumonia in China: a retrospective multicentre survey. BMJ Open. 2018;8:e018709.

18. Hirano K, Imbens GW. The propensity score with continuous treatments. In: Gelman A, Meng X-L, editors. Applied Bayesian modeling and causal inference from incomplete-data perspectives. Hoboken: Wiley; 2004. p. 73-84.

19. Muthuri SG, Venkatesan S, Myles PR, Leonardi-Bee J, Al Khuwaitir TS, Al Mamun A, et al. Effectiveness of neuraminidase inhibitors in reducing mortality in patients admitted to hospital with influenza a H1N1pdm09 virus infection: a meta-analysis of individual participant data. Lancet Respir Med. 2014;2(5):395-404.

20. MacIntyre CR, Chughtai AA, Barnes M, Ridda I, Seale H, Toms R, et al. The role of pneumonia and secondary bacterial infection in fatal and serious outcomes of pandemic influenza a(H1N1)pdm09. BMC Infect Dis. 2018;18(1): 637.

21. Sohn CH, Ryoo SM, Yoon JY, Seo DW, Lim KS, Kim SH, et al. Comparison of clinical features and outcomes of hospitalised adult patients with novel influenza a (H1N1) pneumonia and other pneumonia. Acad Emerg Med. 2013;20(1):46-53.

22. Bothwell LE, Podolsky SH. The emergence of the randomized, Controlled Trial. N Engl J Med. 2016;375(6):501-4.

23. Thiese MS. Observational and interventional study design types; an overview. Biochem Med (Zagreb). 2014;24(2):199-210.

24. Turner DP, Houle TT. Observational study designs. Headache. 2019:59(7): 981-7.

25. Muthuri SG, Venkatesan S, Myles PR, Leonardi-Bee J, Lim WS, Al Mamun A, et al. Impact of neuraminidase inhibitors on influenza a(H1N1)pdm09related pneumonia: an individual participant data meta-analysis. Influenza Other Respir Viruses. 2016;10(3):192-204.

26. Louie JK, Yang S, Acosta M, Yen C, Samuel MC, Schechter R, et al. Treatment with neuraminidase inhibitors for critically ill patients with influenza a (H1N1)pdm09. Clin Infect Dis. 2012;55(9):1198-204.

27. Miller PE, Rambachan A, Hubbard RJ, Li J, Meyer AE, Stephens P, et al. Supply of neuraminidase inhibitors related to reduced influenza a (H1N1) mortality during the 2009-2010 H1N1 pandemic: summary of an ecological study. Influenza Other Respir Viruses. 2013;7(Suppl 2):82-6.

28. Higuera Iglesias AL, Kudo K, Manabe T, Corcho Berdugo AE, Corrales Baeza A, Alfaro Ramos L, et al. Reducing occurrence and severity of pneumonia due to pandemic H1N1 2009 by early oseltamivir administration: a retrospective study in Mexico. PLoS One. 2011;6(7):e21838.

29. Choi SH, Kim T, Park KH, Kwak YG, Chung JW, Lee MS. Early administration of neuraminidase inhibitors in adult patients hospitalised for influenza does not benefit survival: a retrospective cohort study. Eur J Clin Microbiol Infect Dis. 2017;36(9):1673-7.

30. Lee N, Choi KW, Chan PK, Hui DS, Lui GC, Wong BC, et al. Outcomes of adults hospitalised with severe influenza. Thorax. 2010;65(6):510-5.

31. Deyde VM, Sampath R, Gubareva LV. RT-PCR/electrospray ionization mass spectrometry approach in detection and characterization of influenza viruses. Expert Rev Mol Diagn. 2011;11(1):41-52.

32. Ito Y. Clinical diagnosis of influenza. Methods Mol Biol. 1836;2018:23-31.

33. Binnicker MJ, Espy MJ, Irish CL, Vetter EA. Direct detection of influenza a and $B$ viruses in less than 20 minutes using a commercially available rapid PCR assay. J Clin Microbiol. 2015;53(7):2353-4.

34. Hazelton B, Gray T, Ho J, Ratnamohan VM, Dwyer DE, Kok J. Detection of influenza $a$ and $B$ with the Alere ${ }^{T M}$ influenza a \& B: a novel isothermal nucleic acid amplification assay. Influenza Other Respir Viruses. 2015;9(3):151-4.

35. Sakai-Tagawa Y, Ozawa M, Tamura D, Le M, Nidom CA, Sugaya N, et al. Sensitivity of influenza rapid diagnostic tests to H5N1 and 2009 pandemic H1N1 viruses. J Clin Microbiol. 2010;48(8):2872-7. 
36. Hwang Y, Kim K, Lee M. Evaluation of the efficacies of rapid antigen test, multiplex PCR, and real-time PCR for the detection of a novel influenza a (H1N1) virus. Korean J Lab Med. 2010;30(2):147-52.

37. de la Tabla VO, Antequera P, Masiá M, Ros P, Martin C, Gazquez G, et al. Clinical evaluation of rapid point-of-care testing for detection of novel influenza a (H1N1) virus in a population-based study in Spain. Clin Microbiol Infect. 2010;16(9):1358-61.

38. Cedraschi C, Saya L, Klein P, Bordet MF, Carrat F. Representations of influenza and influenza-like illness in the community--a qualitative study. BMC Fam Pract. 2013;14:15.

39. Michiels B, Thomas I, Van Royen P, Coenen S. Clinical prediction rules combining signs, symptoms and epidemiological context to distinguish influenza from influenza-like illnesses in primary care: a cross sectional study. BMC Fam Pract. 2011;12:4.

40. Yang SG, Cao B, Liang LR, Li XL, Xiao YH, Cao ZX, et al. Antiviral therapy and outcomes of patients with pneumonia caused by influenza a pandemic (H1N1) virus. PLoS One. 2012;7(1):e29652.

41. Ishiguro T, Kagiyama N, Uozumi R, Odashima K, Takaku Y, Kurashima K, et al. Clinical characteristics of influenza-associated pneumonia of adults: clinical features and factors contributing to severity and mortality. Yale J Biol Med. 2017;90(2):165-81.

42. Viasus D, Paño-Pardo JR, Pachón J, Riera M, López-Medrano F, Payeras A, et al. Pneumonia complicating pandemic (H1N1) 2009: risk factors, clinical features, and outcomes. Medicine (Baltimore). 2011:90(5):328-36.

43. Kossyvakis A, Mentis AA, Tryfinopoulou K, Pogka V, Kalliaropoulos A, et al. Antiviral susceptibility profile of influenza a viruses; keep an eye on immunocompromised patients under prolonged treatment. Eur I Clin Microbiol Infect Dis. 2017;36(2):361-71.

44. Abed Y, Boivin G. A Review of Clinical Influenza A and B Infections With Reduced Susceptibility to Both Oseltamivir and Zanamivir. Open Forum Infect Dis. 2017;4(3):ofx105.

\section{Publisher's Note}

Springer Nature remains neutral with regard to jurisdictional claims in published maps and institutional affiliations.

Ready to submit your research? Choose BMC and benefit from:

- fast, convenient online submission

- thorough peer review by experienced researchers in your field

- rapid publication on acceptance

- support for research data, including large and complex data types

- gold Open Access which fosters wider collaboration and increased citations

- maximum visibility for your research: over $100 \mathrm{M}$ website views per year

At $\mathrm{BMC}$, research is always in progress.

Learn more biomedcentral.com/submissions 